\title{
IK EQUATIONS \& MODELING FOR SCARA ROBOTS
}

Dr. T.C.Manjunath, Ph.D. (IIT Bombay), FIETE, MIEEE

Principal, HKBK College of Engg., 22 / 1, Nagawara, Arabic College Post, B'lore-45, Karnataka

Email : manjuiitb@yahoo.com Phone : +91 9449820361

Dr. Vaibhav A Mesram, B.Tech. (NIT Kurukshetra), M.Tech. (IIT Bombay), Ph.D. (BITS Pilani), M-IEEE, F-IETE Professor, PG Studies \& Research, HKBK College of Engg., Bangalore-45, Karnataka.

Email : vam_25@yahoo.com Phone : +919886831746

\begin{abstract}
The paper presents the backward kinematics analysis, modeling equations for a 4 axis robot.

Index Terms - SCARA Robot, Computer Control
\end{abstract}

\section{INTRODUCTION}

Robotics is an interdisciplinary field that mixes various engineering disciplines such as electrical, electronics, instrumentation, mechanical, computer science, control engineering, mathematics, communications and many other fields into one. In this, work a unique 4 axes system is designed and fabricated with indigenous components with a brief kinematic analysis of the designed robot. The kinematically modeled designed robot is used for performing some PNP operations and was named as a Selective Compliance Assembly Robot Arm (SCARA). The primary motive behind the work was to develop a modular educational robotic system, the CRUST 2002 (Computerized Robotic Unit with Selective Tractability system) with the help of locally available components and sub-systems as shown in Fig. 1 and also to develop a user friendly GUI to control it [1].

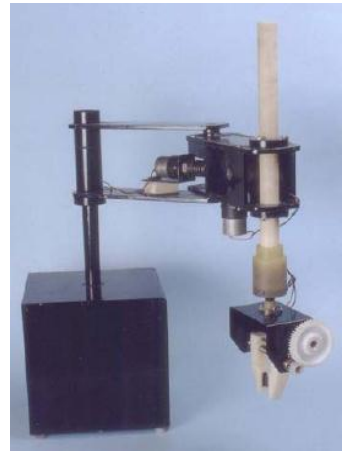

Fig. 1. The designed SCARA robot

\section{PHYSICAL STRUCTURE DESIGN}

A four axis / four DOF designed SCARA robot arm as shown in Fig. 1. A SCARA robot is a 4 DOF stationary robot arm having base, elbow, vertical extension and tool roll and consisting of both rotary and prismatic joints [2]. There is no tool yaw and tool pitch (only tool roll) [1]. There are 4 joints, 4 axis (three major axes - base, elbow, vertical extension and one minor axis - tool roll). The 4 DOF's are given by Base, Elbow, Vertical Extension and Tool Roll, i.e., there are three rotary joints and one prismatic joint. Since $n=4 ; 16$ KP's are to be obtained and 5 RHOCF's are to be attached to the various joints [3].

The vector of joint variables is a combination of $\theta$ and d, i.e., $q=\{\theta$, $d$ \}$^{\mathrm{T}}$. 
Vector of joint variables are $\mathrm{q}=\left\{\theta_{1}\right.$, $\left.\theta_{2}, \mathrm{~d}_{3}, \theta_{4}\right\}^{\mathrm{T}}$.

Vector of joint distances are

$\mathrm{d}=\left\{\mathrm{d}_{1}, 0, \mathrm{~d}_{3}, \mathrm{~d}_{4}\right\}^{\mathrm{T}}=\left\{877,0, \mathrm{~d}_{3}\right.$, $200\}^{\mathrm{T}} \mathrm{mm}$.

Vector of link lengths are

$\mathrm{a}=\left\{\mathrm{a}_{1}, \mathrm{a}_{2}, 0,0\right\}^{\mathrm{T}}=\{425,375,0$, $0\}^{\mathrm{T}} \mathrm{mm}$.

Vector of link twist angles are

$\alpha=\left\{\alpha_{1}, \alpha_{2}, 0, \alpha_{4}\right\}^{\mathrm{T}}=\{ \pm \pi, 0,0$, $0\}^{\mathrm{T}}$.

All the 4 joint axes are vertical in nature (all the $\mathrm{z}$ - axes can be pointing down or up) as shown in Fig. 3. The first three (B, E, VE) axes are called

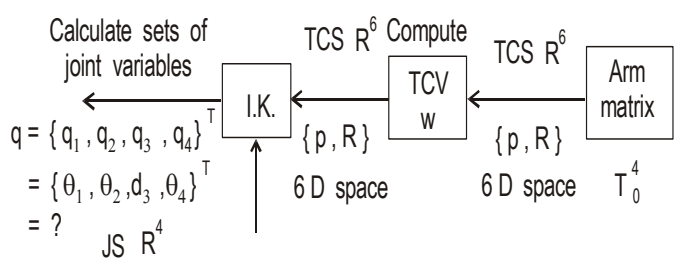

Fig. 3. Inverse Kinematic Model of the robot

\section{DEVELOPMENT OF THE LCD AND KPT}

The analysis of the robot is developed in 2 passes, viz., development as the major axes and are used for positioning the wrist, while the last one, the minor axes ( TR ) is used to orient the tool in the direction of the object [4]. The $1^{\text {st }} 3$ major axes determines the shape and size of work envelope. It consists of a $\mathrm{L}$ shaped structure, to the end of which the second link is attached. There are two links $\mathrm{a}_{1}$ and $\mathrm{a}_{2}$ which move parallel to the work surface ; The vertical extension $d_{3}$ is variable and moves in a direction $\perp^{\mathrm{r}}$ to the work surface; the length of the gripper / tool / EE is $d_{4}$ [2].

\section{BLOCK DIAGRAM OF THE INVERSE KINEMATIC MODELING}

of the link coordinate diagram as shown in Fig. 4 and development of the kinematic parameter table as shown in the Table 1 [10]. The link coordinate diagram is developed as shown in the Fig. 6 with the kinematic parameter table as shown in Table 1 [2].

\section{COMPUTATION OF THE JOINT VARIABLES}

The output of the direct kinematics of the SCARA is [2]

$$
\mathrm{T}_{\text {Base }}^{\text {Tool }}=\mathrm{T}_{0}^{4}=\left[\begin{array}{cccc}
\mathrm{C}_{1-2-4} & \mathrm{~S}_{1-2-4} & 0 & \mathrm{a}_{1} \mathrm{C}_{1}+\mathrm{a}_{2} \mathrm{C}_{1-2} \\
\mathrm{~S}_{1-2-4} & -\mathrm{C}_{1-2-4} & 0 & \mathrm{a}_{1} \mathrm{~S}_{1}+\mathrm{a}_{2} \mathrm{~S}_{1-2} \\
0 & 0 & -1 & \mathrm{~d}_{1}-\mathrm{q}_{3}-\mathrm{d}_{4} \\
0 & 0 & 0 & 1
\end{array}\right]
$$


The Tool Configuration Vector (TCV) is given by [2] [9]

$$
\mathrm{w}(\mathrm{q})=\left[\begin{array}{c}
\mathrm{a}_{1} \mathrm{C}_{1}+\mathrm{a}_{2} \mathrm{C}_{1-2} \\
\mathrm{a}_{1} \mathrm{~S}_{1}+\mathrm{a}_{2} \mathrm{~S}_{1-2} \\
\mathrm{~d}_{1}-\mathrm{q}_{3}-\mathrm{d}_{4} \\
\ldots \ldots \ldots \ldots \ldots \\
0 \\
0 \\
-\exp \left(\frac{\mathrm{q}_{4}}{\pi}\right)
\end{array}\right]
$$

Note : To find out $\mathrm{q}_{1}, \mathrm{q}_{2}, \mathrm{q}_{3}, \mathrm{q}_{4}$; apply row operations used in mathematics to the components of $\mathrm{w}$ using various trigonometric identities [2], [11].

To Extract Elbow Joint Variable $q_{2}=\theta_{2}$

$$
\begin{aligned}
& \cos \mathrm{q}_{2}=\frac{\mathrm{w}_{1}^{2}+\mathrm{w}_{2}^{2}-\mathrm{a}_{1}^{2}-\mathrm{a}_{2}^{2}}{2 \mathrm{a}_{1} \mathrm{a}_{2}} \\
& \mathrm{q}_{2}= \pm \cos ^{-1}\left[\frac{\mathrm{w}_{1}^{2}+\mathrm{w}_{2}^{2}-\mathrm{a}_{1}^{2}-\mathrm{a}_{2}^{2}}{2 \mathrm{a}_{1} \mathrm{a}_{2}}\right] \\
& \mathrm{Eq}^{\mathrm{n}} \quad 3.12: 4 \\
& \mathrm{q}_{2}= \pm \operatorname{arc} \cos \left(\mathrm{w}_{1}{ }^{2}+\mathrm{w}_{2}{ }^{2}-\mathrm{a}_{1}{ }^{2}-\mathrm{a}_{2}{ }^{2}, 2 \mathrm{a}_{1} \mathrm{a}_{2}\right) \quad \mathrm{Eq}^{\mathrm{n}} \text { 3.12:5 }
\end{aligned}
$$
hence we get two solutions. Hence,

\section{To Extract Base Joint Variable $\mathrm{q}_{1}=\theta_{1}$}

$$
\begin{aligned}
& \mathrm{w}_{1}=\mathrm{a}_{1} \mathrm{C}_{1}+\mathrm{a}_{2} \mathrm{C}_{1-2} \\
& \mathrm{w}_{2}=\mathrm{a}_{1} \mathrm{~S}_{1}+\mathrm{a}_{2} \mathrm{~S}_{1-2}
\end{aligned}
$$

Expand $\mathrm{C}_{12}$ and $\mathrm{S}_{12}$ using sum of sines and cosines; isolate $\mathrm{C}_{1}, \mathrm{~S}_{1}$ write and $S_{1}$ terms, find $A^{-1}$ and $|A|$, solve in matrix form, collect all $\mathrm{C}_{1}$ terms for $q_{1}[2],[15]$.

$$
\begin{gathered}
\mathrm{w}_{1}=\mathrm{a}_{1} \mathrm{C}_{1}+\mathrm{a}_{2}\left(\mathrm{C}_{1} \mathrm{C}_{2}+\mathrm{S}_{1} \mathrm{~S}_{2}\right)=\left(\mathrm{a}_{1}+\mathrm{a}_{2} \mathrm{C}_{2}\right) \mathrm{C}_{1}+\left(\mathrm{a}_{2} \mathrm{~S}_{2}\right) \mathrm{S}_{1} \\
\mathrm{w}_{2}=\mathrm{a}_{1} \mathrm{~S}_{1}+\mathrm{a}_{2}\left(\mathrm{~S}_{1} \mathrm{C}_{2}-\mathrm{C}_{1} \mathrm{~S}_{2}\right)=\left(-\mathrm{a}_{2} \mathrm{~S}_{2}\right) \mathrm{C}_{1}+\left(\mathrm{a}_{1}+\mathrm{a}_{2} \mathrm{C}_{2}\right) \mathrm{S}_{1} \\
\tan \mathrm{q}_{1}=\frac{\mathrm{S}_{1}}{\mathrm{C}_{1}}=\frac{\sin \mathrm{q}_{1}}{\cos \mathrm{q}_{1}}=\left[\frac{\left(\mathrm{a}_{1}+\mathrm{a}_{2} \mathrm{C}_{2}\right) \mathrm{w}_{2}+\left(\mathrm{a}_{2} \mathrm{~S}_{2}\right) \mathrm{w}_{1}}{\left(\mathrm{a}_{1}+\mathrm{a}_{2} \mathrm{C}_{2}\right) \mathrm{w}_{1}-\left(\mathrm{a}_{2} \mathrm{~S}_{2}\right) \mathrm{w}_{2}}\right] \\
\left.\mathrm{q}_{1}=\arctan 2\left\{\left(\mathrm{a}_{1}+\mathrm{a}_{2} \mathrm{C}_{2}\right) \mathrm{w}_{2}+\mathrm{a}_{2} \mathrm{~S}_{2} \mathrm{w}_{1},\left(\mathrm{a}_{1}+\mathrm{a}_{2} \mathrm{C}_{2}\right) \mathrm{w}_{1}-\mathrm{a}_{2} \mathrm{~S}_{2} \mathrm{w}_{2}\right)\right\} \\
\mathrm{q}_{1}=\tan ^{-1}\left\{\frac{\left(\mathrm{a}_{1}+\mathrm{a}_{2} \mathrm{C}_{2}\right) \mathrm{w}_{2}+\left(\mathrm{a}_{2} \mathrm{~S}_{2}\right) \mathrm{w}_{1}}{\left(\mathrm{a}_{1}+\mathrm{a}_{2} \mathrm{C}_{2}\right) \mathrm{w}_{1}-\left(\mathrm{a}_{2} \mathrm{~S}_{2}\right) \mathrm{w}_{2}}\right\}
\end{gathered}
$$

This solution given by this gives the values of the base angle $\mathrm{q}_{1}$ over the complete range $(-\pi,+\pi)$; since, we had used the $\operatorname{arc} \tan 2$ function. Hence, if we use the $\arctan 2$ function, we 
can recover the base angles over the

\section{To Extract Vertical Extension Joint Parameter, $\mathrm{q}_{3}=\mathrm{d}_{3}$}

From the $3^{\text {rd }}$ component of TCV ; $\mathrm{w}$, we have

$\mathrm{w}_{3}=\mathrm{d}_{1}-\mathrm{q}_{3}-\mathrm{d}_{4}$

The $3^{\text {rd }}$ variable $\mathrm{q}_{3}$ is extracted as [13]

$\mathrm{q}_{3}=\mathrm{d}_{1}-\mathrm{d}_{4}-\mathrm{w}_{3}$

To Extract Tool Roll Angle, $\mathrm{q}_{4}=\theta_{4}$ [2]

\section{CONCLUSION}

A four axes inverse kinematic analysis was performed for the designed robot and was successfully implemented in the laboratory. The robot was controlled using a GUI developed in visual basic language in various modes. A number of pick and place operations were successfully performed by the developed robot by using teaching mode, manual mode and programming modes and the inverse kinematic model.

\section{REFERENCES}

[1] Craig J, Introduction to Robotics : Mechanics, Dynamics \& Control, Addison Wessely, USA, 1986.

[2] Robert, J. Schilling, Fundamentals of Robotics - Analysis and Control, PHI, New Delhi.

[3] Klafter, Thomas and Negin, Robotic Engineering, PHI, New Delhi.

[4] Fu, Gonzalez and Lee, Robotics: Control, Sensing, Vision and Intelligence, McGraw Hill. complete range, i.e., $360^{\circ}$ [17], [18]

The tool roll angle is computed from the last component of the TCV, i.e., $\mathrm{w}_{6}[14]$.

From TCV, we have;

$\mathrm{w}_{4}=\mathrm{w}_{5}=0$, i.e., there is no yaw and pitch .

Using the equation [15]

$$
\begin{aligned}
& \mathrm{q}_{\mathrm{n}}=\pi \ln \sqrt{\mathrm{w}_{4}^{2}+\mathrm{w}_{5}^{2}+\mathrm{w}_{6}^{2}}=\pi \ln \\
& \sqrt{0^{2}+0^{2}+\mathrm{w}_{6}^{2}} \\
& \mathrm{q}_{4}=\pi \ln \left|\mathrm{w}_{6}\right|
\end{aligned}
$$

[5] Groover, Weiss, Nagel and Odrey, Industrial Robotics, McGraw Hill.

[6] Ranky, P. G., C. Y. Ho, Robot Modeling, Control \& Applications, IFS Publishers, Springer, UK.

[7] Crane, Joseph Duffy, Kinematic Analysis of Robotic Manipulators, Cambridge Press, UK.

[8] Manjunath, T.C., (2005), Fundamentals of Robotics, Fourth edn., Nandu Publishers, Mumbai.

[9] Manjunath, T.C., (2005), Fast Track to Robotics, Second edn., Nandu Publishers, Mumbai.

[10] William Burns and Janet Evans, (2000), Practical Robotics - Systems, Interfacing, Applications, Reston Publishing Co.

[11] http://www.wikipedia.org

[12] Michael Dipperstein, Run Length Encoding (RLE) Discussion and Implementation.

[13] Flusser, J.; Suk, T.; Saic, S., Recognition of blurred images by the method of moments, Image Processing, IEEE Transactions.

[14] Bob Bailey, Moments in Image Processing, Nov. 2002.

[15] Phillip Coiffette, (1995), Robotics Series, Volume I to VIII, Kogan Page, London, UK.

[16] William Burns and Janet Evans, (2000), Practical Robotics - Systems, Interfacing, Applications, Reston Publishing Co.

[17] Yoshikawa T., (1984), "Analysis and Control of Robot Manipulators with Redundancy", Proc. First Int. Symp. on Robotics Research, Cambridge, MIT Press, pp. 735748. 